\title{
RECONFIGURACIONES IDENTITARIAS A PARTIR DE HABITAR EL ESPACIO PÚBLICO. EL CASO DE LOS MIGRANTES ESQUINEROS EN LA CIUDAD DE SANTIAGO, CHILE
}

\author{
IDENTITY RECONFIGURATIONS BASED ON INHABITING THE PUBLIC SPACE. \\ THE CASE OF DAY LABOR MIGRANTS IN SANTIAGO, CHILE
}

\author{
Carolina Stefoni ${ }^{1}$
}

\begin{abstract}
El artículo explora la vinculación entre las condiciones de vida que enfrentan los y las inmigrantes en la ciudad de Santiago, con las formas de habitar que ellos mismos despliegan en un espacio público específico: una esquina ubicada en el centro histórico y cívico de la ciudad de Santiago, en la que los migrantes concurren cotidianamente a buscar trabajo y compartir con los connacionales. Se sostiene que estas formas de vivir y habitar la esquina se vuelven modos de vivir el proyecto migratorio, en un contexto de sobrevivencia cotidiana donde el trabajo alcanza máximos niveles de precarización. El encuentro, reconocimiento y apropiación de un lugar público posibilita el desarrollo de procesos identitarios que configuran un "nosotros" que se desarrolla a partir de procesos de diferenciación, los que a su vez revierten estigmatizaciones y reafirman posiciones de poder dentro de la propia comunidad de migrantes. De este modo se sostiene que la generación de identidades colectivas se construye a partir de las formas de habitar el lugar y de los procesos de distinción que se generan respecto de la población local y respecto de la propia comunidad de migrantes.

Palabras claves: migración, espacio público, identidades colectivas, esquineros, Santiago de Chile.
\end{abstract}

This article explores the relationship between the socioeconomic conditions of immigrants in Santiago (Chile) and the different forms of inhabiting a particular public space: a corner situated at the civic and historic center of Santiago, where immigrantsmeet on a daily basis to seek for jobs and interact with other nationals. It is argued that the ways in which this corner is inhabited become part of their migratory experience, which is lived in extremely vulnerable and precarious living and working conditions. Encountering others, finding recognition and appropriating the public space, promote the development of a collective identity. The construction of the 'we' occurs through processes of differentiation from the host society and migrant community, which, at the same time, contest forms of stigmatization, and reinforce power positions within the community. Thus, it is argued that collective identities emerge from the ways in which public spaces are inhabited and from processes of differentiation from the local population and from the migrant community itself.

Key words: Migration, public spaces, collective identities, day labor, Santiago de Chile.

El centro histórico, político y urbano de la ciudad de Santiago es un espacio en constante construcción en términos materiales y simbólicos. Las formas de habitar-definidas a partir de las prácticas sociales (De Certeau 2010), la relación con la materialidad (Bonhomme 2013; Miller 1998) y las relaciones sociales que establecen las personas que viven, circulan y trabajan en ese espacio- permiten la apropiación y significación de los lugares en un sentido lefebvriano, esto es en tanto construcción social del espacio (Lefebvre 1991). Un actor que se ha sumado en el último tiempo a la construcción de este lugar, son los extranjeros, quienes han repoblado y transformado la estética, los sabores y colores de las calles y barrios del centro de la ciudad (Ducci y Rojas 2010; Garcés 2014; Imilan 2014; Luque 2007; Margarit y Bijit 2014; Schiapacasse 2008; Stefoni 2013a; 2013b). El objetivo del presente artículo es analizar de qué modo las formas de habitar un lugar determinado, permite el desarrollo de procesos identitarios que configuran un sujeto colectivo (nosotros), que se construye en la distinción respecto de la sociedad de acogida y dentro de la propia comunidad de migrantes.

Debido a que en el centro de la ciudad se distinguen distintas formas de ser y estar (Low y Zúñiga 2003), el lugar escogido en este artículo es la esquina de calle Catedral con Puente, al costado norponiente de la Plaza de Armas. Aquí se reúnen de lunes a viernes una treintena de hombres migrantes

$\overline{1}$ Departamento de Sociología, Universidad Alberto Hurtado, Santiago, Chile. cstefoni @ uahurtado.cl

Recibido: julio 2014. Aceptado: abril 2015.

http://dx.doi.org/10.4067/S0717-73562015005000035. Publicado en línea: 22-agosto-2015. 
a la espera que alguien los lleve a trabajar en la construcción, descargar camiones, trabajo agrícola u otros trabajos por día o de corta duración. La existencia de este tipo de esquinas se repite en diversas ciudades del mundo, y en la bibliografía se les reconoce como esquineros o jornaleros (Valenzuela 2003). En inglés se utiliza day labor, que refiere a hombres que buscan trabajo en espacios descubiertos como estacionamientos, frente a tiendas de construcción o esquinas específicas. Puesto que el caso de estudio refiere a una esquina, se ha optado por el término esquineros.

En términos metodológicos se utilizó un enfoque cualitativo y las técnicas utilizadas fueron observación participante y entrevistas en profundidad. Dado que el objeto de estudio fueron los sujetos migrantes que se ubican en esta esquina, la nacionalidad no fue un criterio de selección para realizar las entrevistas, sin embargo, la mayor presencia de migrantes de origen peruano significó que parte importante de la muestra correspondiera a dicha nacionalidad. Para resguardar la identidad de las personas entrevistadas, se reemplazaron los nombres reales por nombres ficticios.

Siguiendo a Doren Massey (1994), el artículo analiza los mecanismos de distinción que surgen en las formas de habitar que despliegan los migrantes en esta esquina, y propone que estos elementos de distinción favorece el desarrollo de un sujeto colectivo. El trabajo de campo muestra que lejos de ser una categoría unitaria u homogénea, la construcción del nosotros en cuanto sujeto colectivo, se constituye en procesos simultáneos de diferenciación y reconocimiento respecto de la propia comunidad de migrantes, y de la sociedad de llegada.

El artículo analiza dos procesos de diferenciación que llevan a cabo los esquineros: (i) la figura del 'buen trabajador' que actúa como ideal normativo de migrante, diferenciándolo de los malos trabajadores extranjeros y de los empleadores y trabajadores chilenos, y (ii) la condición masculina de los esquineros que se ejerce durante la semana, gracias a la distinción respecto de la mujer migrante, a quien se le excluye del habitar este espacio público, ya que amenazaría el orden de género en el que se sustenta la masculinidad del trabajador migrante.

En la primera distinción los migrantes logran revertir la posición de subordinación de la que son objeto por la sociedad de acogida, construyendo un discurso de legitimación y reivindicación respecto de aquello que busca dominarlos. Se trata de prácticas de resistencia (De Certeau 2010; Kuper 2003) frente a las múltiples formas de dominación presentes en la sociedad de llegada, sin embargo es necesario preguntarse si dichas reivindicaciones logran traspasar el orden simbólico para introducir transformaciones sociales en el mundo material. La segunda distinción da cuenta de cómo las prácticas sociales, relaciones y materialidades que se despliegan y configuran el habitar, reafirman también estructuras de poder presentes en las sociedades de origen, como la condición masculina frente a la femenina. Así la forma de habitar la esquina permite no solo una reivindicación frente a lo chileno, sino también una reproducción del orden de género por medio de la distinción público/privado, esto es hombres en la calle y mujeres relegadas al ámbito doméstico, sea privado o laboral.

La primera parte del artículo describe las prácticas que despliegan los esquineros y analiza la figura del buen maestro como elemento diferenciador. La segunda analiza la posición espacial asignada a la mujer migrante, a quien se le excluye de participar durante los días de semana de la esquina, reforzando la idea de que debe permanecer en el ámbito de lo privado y continuar, desde ahí, su rol de madre a la distancia. Finalmente se analiza la configuración de un "nosotros migrantes" a partir de estos procesos de diferenciación y construcción de identidades.

\section{Identidades a Partir del Trabajo por día: La Figura del Buen Maestro como Elemento Diferenciador para la Configuración del Buen Migrante}

En la calle Catedral, a un costado de la Plaza de Armas (lugar donde se funda la ciudad de Santiago), entre las calles Puente y Bandera, se observa de lunes a viernes a una treintena de hombres inmigrantes sentados al costado de la iglesia esperando que alguien llegue a ofrecer trabajo, los seleccione y los lleve. Arturo señala que la mayoría de los trabajos se obtienen entre las 7.30 a.m. y la media mañana, sin embargo, hasta cerca de las ocho de la noche hay personas inmigrantes en la esquina, lo que le otorga un carácter especial, pues no se trata solo de un lugar para buscar trabajo, sino que hace parte de un espacio de recreación y encuentro para este grupo de personas.

Los trabajos que se ofertan están vinculados mayoritariamente a especialidades de la construcción: 
pintores, ceramistas, estucadores, gasfitería, albañilería y electricista. Se trata de pequeñas empresas que requieren personas con distintos niveles y tipos de oficios para arreglos de casas u obras pequeñas. Otros trabajos disponibles son descargador de camiones y trabajos en predios agrícolas. El primero es un trabajo por hora donde el pago se realiza de forma inmediata (\$5.000 la hora, unos US\$10), lo que permite "sacar el día", es decir, comer algo y pagar la locomoción. El segundo es estacional y requiere que las personas se queden en los predios por el tiempo necesario para terminar la cosecha.

Los trabajos que aquí se ofrecen son por día o un par de semanas como máximo, no tienen contrato ni pago de imposiciones, lo que dificulta el acceso a los servicios sociales como salud, a la vez que excluye de derechos laborales como las licencias médicas, seguro de desempleo y ahorro en el sistema previsional. De acuerdo con Waldinger $(1986,2008)$ el no pago de seguridad social actúa como incentivo para que la pequeña empresa busque en este sector a sus trabajadores. De este modo, el margen para que se cometan abusos hacia los trabajadores es amplio (sobreexplotación, no pago del salario y jornadas extensas) y cuando sucede, los trabajadores no pueden acceder a los mecanismos formales de protección laboral.

El trabajo disponible es informal y precario, pero no es una actividad que pueda pensarse como una transición hacia el trabajo formal, ni una actividad disponible para los recién llegados o los más excluidos dentro de un mercado laboral ya segregado. El trabajo por día es más bien parte de un continuo entre el trabajo formal y el informal, un estado intermedio que permite que lo formal y lo informal sean parte de un mismo sistema laboral (Tokman 2001). Esta forma de precarización extrema responde a tendencias globales que señala Sassen (2003) en donde el trabajo es cada vez menos seguro. Las características y condiciones laborales que enfrentan los esquineros coincide completamente con la definición de trabajo precario que entrega Cárdenas et al. (2012): trabajo frágil, impredecible e inseguro, donde los riesgos son asumidos por el trabajador en vez de la empresa o el Estado. El trabajo precario es resultado de estrategias de gestión por parte de los empleadores, cuya función es reducir costos, limitar o reducir el número de trabajadores permanentes, maximizar la flexibilidad de las empresas y trasladar riesgos a los trabajadores
(Cárdenas et al. 2012:42). Así, el trabajo por día se puede ubicar en el extremo de una modalidad que se globaliza con rapidez, y que suele darse con fuerza en sectores de mayor concentración de migrantes (Bauman 2006; Sassen 2003; Valenzuela 2003, 2001; Zlolniski 2006).

Los esquineros prefieren negociar directamente con quien realiza la obra, pues el contratista al ser intermediario, paga menos y en ocasiones los hace trabajar mucho más; prefieren también un pago semanal o quincenal sobre el mensual, esto porque hay numerosos casos en donde los contratistas pagan menos de lo acordado o incluso a veces, desaparecen sin pagar. El pago semanal o diario es más seguro, porque como señalan los entrevistados, si no les pagan, al menos es menos el tiempo que se pierde. Los entrevistados tienden a asociar al contratista con un chileno, respecto del cual hay que tener cuidado porque puede aprovecharse del trabajador inmigrante:

Pero aquí hay que tener mucho cuidado con el contratista chileno, es muy pillo en el sentido [de que] te hace trabajar, se termina el trabajo y ya no lo ves más. Pasa continuamente, está acostumbrado. ¡Disculpa, no te vayas a molestar!, al contratista chileno yo lo veo sinvergüenza, estafador, que roba nuestro trabajo, se lucra con ello (Arturo, hombre peruano).

La negociación del pago depende de la experiencia y conocimiento del trabajador. Los maestros calificados gozan de mayor prestigio y piden una tarifa alta que puede llegar a los $\$ 25.000$ o \$ 30.000 diarios (US\$ 50-US\$ 60). Este es un tema de orgullo para muchos de los que están ahí. El maestro peruano sabe, tiene conocimiento de todo el campo de la construcción. Los otros -incluidos los chilenos y también los inmigrantes que "se hacen pasar por maestros"- tienen solo un conocimiento parcial.

Mire, allá en Perú la palabra maestro significa... el maestro peruano tiene conocimiento en albañilería, gasfitería, electricidad, todo lo que es techumbre, pintura, ese es un maestro peruano. Los otros son, solamente que, que conocen un solo ramo. Acá el chileno dice soy maestro carpintero, soy maestro pintor, maestro 
huinchador, pero no conocen en la totalidad (Arturo, hombre peruano).

El verdadero maestro, aquel que sabe su oficio, tiene una tarifa alta entre los $\$ 400.000$ y $\$ 500.000$ mensuales (US\$ 800-US\$1000). Por menos plata no van, señala uno de los entrevistados.

Entrevistador: es un buen sueldo ese. Entrevistado: al menos, este, hay gente que, al menos yo no trabajo por menos plata. Prefiero decirle sabes que, hasta luego, que vaya otra gente, y no voy (Arturo, hombre peruano).

Entre ellos se reconocen quiénes son y quiénes no son maestros, sin embargo lo importante es que el otro, el empleador, pueda identificarlos en medio de todos los trabajadores. Para ello, el maestro utiliza el bolso como elemento material diferenciador. "Al maestro peruano se le reconoce porque anda con su bolso con herramientas", señala una de las personas con quien conversé al principio de la investigación. Así, el bolso se transforma en parte del atuendo material que lo distingue y le permite ser reconocido como un maestro de verdad. Dentro del bolso lleva ropa y herramientas necesarias para realizar el trabajo.

La figura del maestro opera como eje en torno al cual se construye y representa al trabajador peruano: 'buen trabajador', 'sabe el oficio', 'responsable', 'honesto' y cuando es contratista, 'no se queda con tu plata, te lo paga, no es como acá'. Esta construcción opera de manera naturalizada, pues se asume como una condición propia del peruano que se adquiere desde la niñez.

Pero (el peruano) es trabajador, está formado para el trabajo, porque hay exigencia de trabajo, piensa que desde su niñez está formado bajo exigencia (Artemio, hombre peruano).

La naturalización del buen trabajador es una forma de construcción racializada del inmigrante (Caggiano 2008; Tijoux 2011; Wieviorka 2002) que es utilizada por ellos mismos como una estrategia para obtener trabajo. Son estas mismas características las que le permiten diferenciarse del trabajador chileno, a quien ellos ven como 'flojo', 'mentiroso', 'sacador de vuelta' y que cuando es contratista es 'capaz de engañar a sus trabajadores'. Esta distinción por oposición y naturalizada permite que el inmigrante peruano se muestre como una buena opción a contratar, permite ganarse un espacio dentro del competitivo mundo informal y darle valor a su trabajo. El buen maestro peruano se inscribe, por lo tanto, dentro de un sistema que permite reorganizar el orden social en el que se encuentra y valorizar la posición que apuesta por ocupar: dejar de ser cualquier maestro de la construcción para ser reconocido como un maestro de calidad $\mathrm{y}$, por tanto, necesario.

El problema es que la distinción que sostiene el prestigio que reclama, es precaria y está bajo constante amenaza. Las amenazas vienen de múltiples partes, pero sobre todo de las prácticas de los propios inmigrantes, por ejemplo, cuando una persona sin experiencia cobra más barato por su trabajo. En estos casos, el empleador puede optar por esa persona, pero se dará cuenta muy tarde que no sabía el oficio. Este acto es sancionado por los pares porque pone en riesgo la diferenciación y valor del maestro peruano en relación con el chileno.

Una segunda forma de poner en riesgo este prestigio es que el 'trabajador peruano se chilenice', es decir, deje de ser aquel trabajador honesto y responsable y adquiera los vicios del chileno. Esto es simplemente fatal para el trabajador inmigrante, pues se esfuma aquello que lo valida, que lo hace necesario y deseado por la sociedad chilena. Si el trabajador adquiere los vicios del chileno, entonces el empleador no tendrá ningún motivo para contratarlo, ya que en igualdad de condiciones, lo más seguro es que se incline por el connacional.

Entrevistado: La gente peruana es muy responsable, cuando se vuelve irresponsable, se malogró y ya no lo cambias más. Es que se está poniendo mentiroso el peruano, se está chilenizando (risas), es la pura verdad, se está volviendo flojo. El chileno es flojo. Entrevistador: ¿Por qué cree que el peruano se está chilenizando?

Entrevistado: Porque se va pa allá, ve que el chileno no trabaja y se pone flojo, no trabaja. El chileno le dice, no, compadrito, deje la pega... se está chilenizando. Al principio no, los primeros peruanos que llegaron acá eran responsables, eran respetados en la pega. Yo trabajé siete años en Metrogas, nunca falté al trabajo. Me mandaron a 
estudiar, todo y nunca falté. Pero después conocí gente que se puso irresponsable, cae al vicio, la clásica del borracho, se está poniendo irresponsable el peruano (Bernardo, hombre peruano).

El trabajador que se 'chileniza' experimenta una aculturación negativa, una práctica que en este caso recibe la sanción de los demás migrantes que trabajan en este rubro. La sanción es la separación del grupo, su alejamiento radical, pues 'cuando se vuelve irresponsable, se malogró y ya no lo cambias más'. El chilenizarse es un camino sin retorno.

Con esta distinción los esquineros invierten simbólicamente el orden social que los posiciona en una condición de inferioridad y subordinación, pues la figura del buen maestro cuestiona una serie de estereotipos y representaciones negativas de la que ellos son objeto.

El buen maestro es aquel que obtiene reconocimiento por parte del empleador, lo que se traduce en que podrá ser nuevamente convocado. Ahora bien, la valoración que realiza el empleador puede basarse efectivamente en la calidad del trabajo, pero también al considerar que tiene buena disponibilidad y resistencia al trabajo ("trabaja sin alegar'). El maestro migrante deberá ajustar sus prácticas y relaciones con estas expectativas y podrá negociar ciertas condiciones laborales a partir de ello. La paradoja es que la valoración del trabajador inmigrante proviene precisamente de las condiciones que le permiten ser explotado y maltratado.

La posibilidad de alcanzar el tan deseado reconocimiento (en cuanto mano de obra) explica en parte la valoración que le dan los esquineros al trabajo independiente, ya que como plantea Zlolniski (2006), el autoempleo y/o empleo precario no debe ser entendido como la última alternativa de trabajo frente a la exclusión y marginación del mercado laboral tradicional. El autor señala que hay cierta elección de este tipo de trabajo, que se sostiene en una valoración a la ausencia de jefatura directa, ser dueño de los tiempos personales, disponer de tiempo de ocio y trabajar porque se quiere, $\mathrm{y}$ no por obligación. De acuerdo con el estudio realizado, la posibilidad de ganar reconocimiento y prestigio frente a la propia comunidad de migrantes es un factor adicional que explicaría la opción de permanecer bajo esta modalidad de trabajo.

¿Es la obtención de una visa un factor decidor en el tipo de trabajo y condiciones laborales a las que accede la población migrante? Diversos estudios sobre inserción laboral de la población migrante muestran que las personas en situación irregular acceden a trabajos más precarios y vulnerables. El caso chileno no es una excepción (Solimano et al. 2012; Stefoni 2011; Thayer 2011; 2013; Tijoux 2011), sin embargo quienes se ubican en la esquina de calle Catedral a la espera de trabajos por día, en su mayoría están con los papeles al día. Ello se explica por los altos niveles de vigilancia que se han instalado en el centro de la ciudad, y que hace muy difícil que personas sin papeles circulen tranquilamente por las calles. Ello no quiere decir que en el trabajo por día se empleen solo personas en situación regular, pues hay otros sistemas de reclutamiento, ya sea en otras esquinas menos visibles, o bien por redes y contactos.

\section{Relaciones de Género que dan Forma a la Esquina de Catedral. La Calle No es para las Buenas Mujeres}

La incorporación del género en los estudios sobre lugares y espacios se produce a partir de una lectura crítica respecto de la vinculación entre el desarrollo de la economía capitalista y la construcción del espacio que hicieran autores como Harvey (2003) y Castells (1999). La crítica apunta al excesivo determinismo económico que termina por volver al espacio en un producto de las formas de producción, en la medida en que las prácticas y procesos que permiten la reproducción social estarían a la base de las concepciones objetivas del tiempo y del espacio (Harvey 1990, 2003).

Si bien se considera que la relación entre espacio social y economía es fructífera en cuanto a generación de estudios, Doreen Massey (1994) señala que es limitada en términos de sus alcances. La autora critica la aproximación de Harvey por considerarlo extremadamente economicista y plantea que no solo la condición de clase determina cómo se vive y construye el espacio, sino también la condición de género y la etnia. La autora ejemplifica señalando que las formas de concebir y vivir el espacio que tiene un alto ejecutivo de una empresa multinacional, son muy distintas a las nociones de espacio que tiene una mujer somalí que debe recorrer a pie varios kilómetros para ir en busca de agua (Massey 1994). En este sentido la autora argumenta que condiciones de género, etnia y clase determinan, en conjunto, la forma en cómo se experimenta el espacio y cómo 
se concibe y construye la espacialidad que rodea a los sujetos.

El trabajo de Massey así como el de Bourdieu (1998) influyeron significativamente en los estudios sobre espacios desde una perspectiva de género. $\mathrm{Si}$ bien hay elementos estructurales que van estableciendo las posibilidades de las prácticas, como lo señala Bourdieu (1998) en el estudio de la casa Kabyle, también hay espacio para subvertir ese orden, transformarlo y redefinirlo (De Certeau 2010; Massey 1994).

¿En qué medida el género estructura las formas de uso, las prácticas y las relaciones sociales que construyen los espacios? Ardener plantea que los espacios poseen reglas de acceso, de comportamiento, de pertenencia, y que al igual que el género, se trata de un principio ordenador de las relaciones sociales (Ardener 1993). Para ello es habitual encontrar formas de organización basadas en sistemas duales como izquierda/derecha; arriba/abajo; dentro/fuera; oriente/poniente; centro/periferia, público/privado, entre otros. Estos sistemas responden a estructuras de significado y sentido que ordenan, restringen y posibilitan las prácticas y relaciones sociales. Ello explica el fuerte carácter masculino presente en la esquina estudiada, durante los días de semana. Se trata principalmente de hombres que están ahí, que habitan esa vereda y en ese habitar, la resignifican y la hacen propia. Las mujeres que se observan en el sector, en cambio, tienden a caminar por la calle, van a la galería, entran y salen de las cabinas de teléfono y agencias de envío de dinero, entran a almorzar en algún negocio cercano. Se trata de prácticas de visita, de entrar y salir, de pasar, de ir por un rato mientras dura el tiempo libre del que disponen en sus trabajos (Stefoni 2013b). Ellas no están en la esquina de calle Catedral, no se quedan, y por lo tanto, la habitan de una manera distinta. La disfrutan, utilizan sus servicios y acompañan a sus parejas. Para el hombre, estar cotidianamente en la esquina es lo que posibilita su apropiación, en cambio la mujer tiene una presencia efímera y momentánea. El uso que hace de la calle es distinto, lo que le impide apropiarse de este espacio, y cuando lo habita de manera similar a como lo hacen los hombres, la sospecha cae sobre ella.

Los entrevistados señalan que la presencia de mujeres en la esquina de la Catedral durante la semana y en espacios semipúblicos como los clubes, encierra el peligro de que se 'pierdan' y olvidar lo que son.
Entrevistado: (...) acá (la mujer) se siente libre, encuentra su necesidad sexual que nunca la tuvo, prácticamente es como si recién se enamorara la persona, se olvida de los hijos de la familia, por qué, porque la mujer que trabaja acá tiene más economía que el hombre, porque la mujer trabaja puertas adentro no gasta alimentación, pasaje, vivienda, el hombre acá es diferente tiene gastar lo que le acabo de mencionar. Por eso es que la mujer tiene mucha perdición, son pocos los que se mantienen (con la cabeza fría) (Don Artemio, hombre peruano).

La vida como migrante en Santiago representaría una liberación de las condiciones de opresión en la que ellas vivían. Don Artemio reconoce que en Perú, los hombres, sean esposos o padres, coartan la libertad de las mujeres. Otro entrevistado señala que las mujeres en Perú están bajo el control de sus padres, y que la llegada a Chile significa una liberación de esas ataduras.

Acá se sienten como libres, tienen una libertad que no obtienen allá en Perú. Allá no pueden salir a fiestas, no pueden hacer muchas cosas porque sienten el control de sus padres, pero acá es como abrirle la puerta a un perrito que nunca ve calle, corretea, salta por todos lados y hace lo que quiere, sin control, eso es lo que pasa (Arturo, hombre peruano).

En estos relatos (de hombres) se representa a la mujer como alguien que no sabe manejar la libertad que adquiere en el extranjero. Se construye la idea de que no tiene suficiente criterio o raciocinio para administrar esa libertad, como modo de justificar el control masculino que se sigue ejerciendo sobre ellas. En estos términos la ausencia de control, ya sea propio o bien externo, generaría las condiciones propicias para que las mujeres crucen la frontera que separa la 'decencia' de la 'indecencia', la 'buena' de la 'mala' mujer. El riesgo de cruzar esta frontera y 'perderse' implica dejar de ser la buena madre-migrante, es decir, olvidar la razón de la migración, esto es trabajar para alimentar a sus hijos y familia.

En la entrevista a don Artemio esta pérdida de control alude al ámbito sexual y tiene como 
consecuencia el agravante caer bajo el dominio del hombre chileno.

La mujer, uno de que acá por intermedio de internet de las amistades va a una fiesta, y no está preparada en el ambiente sexual al que llegó. Entonces es fácil de manejarla por el chileno, el chileno lo maneja porque es más hábil en el campo sexual, en una reunión acá el chileno busca una dama peruana, como a mujer peruana es más sensible, el aprovecha para hacer eso, la mujer peruana siempre ha estado frustrada y el chileno se aprovecha de eso, lo vuelve un punto débil donde es manejado por todos y como nunca vivió esa parte sexual, entonces esa mujer rompe esa barrera, se dedica al copete, se olvida de la familia (don Artemio, hombre peruano).

Para el entrevistado, el hombre chileno aparece como un sujeto que se aprovecha de un mayor conocimiento en materia sexual y engaña a la mujer peruana. Una vez que ella acepta al hombre chileno, rompe nuevamente la frontera, pues se abandonaría su rol en cuanto mujer madre inmigrante.

Esta es la transformación negativa a la que están expuestas las mujeres. No es 'chilenizarse' lo que la lleva a dejar de ser una persona honesta, trabajadora, confiable, sino el entregarse al dominio del hombre chileno, creer en sus palabrerías y dejarse dominar por 'el otro'. Ello se representa bajo la idea de cruzar la frontera ('romper la barrera'), es decir, dejar de ser una buena inmigrante, mujer trabajadora y protectora de su familia. Aquí aparece un sistema de diferenciación que permite mantener las relaciones de poder que sustentan el orden de género en la comunidad migrante.

\section{Formas de Habitar el Lugar: entre la Fragilidad del Estar y la Seguridad del Ser}

La esquina se construye a partir de los usos que los migrantes le dan, las prácticas que ahí se realizan y las relaciones o vínculos sociales que se despliegan. Pero al igual que el resto de la calle, los significados que se van construyendo a partir de este habitar, no son ni homogéneos ni unitarios. Más bien, al observar las distintas prácticas y al comprender el carácter ambivalente que presentan las relaciones sociales que ahí se despliegan, emergen distintos significados. Así, la esquina es un lugar masculino en el que se va a buscar trabajo e información, pero a la vez es un lugar para ir a compartir, descansar, conversar y comer. En la esquina las relaciones que se generan son vínculos de pertenencia y reconocimiento entre iguales, pero son simultáneamente vínculos precarios y amenazados. Esto va construyendo un doble carácter, ya que se trata de un lugar de relaciones pragmáticas que permiten acceder a trabajos, a la vez es una especie de esquina de barrio en la que los vecinos se reúnen en los tiempos libres (Stefoni 2013a).

Esta forma de habitar la esquina es consecuencia de la precariedad laboral que se sostiene en relaciones sociales significativas, estratégicas, pero a la vez frágiles y pasajeras. Significativas y estratégicas porque de ellas dependen los trabajos y la información que se consigue, pero frágiles porque estos vínculos pueden romperse en cualquier momento. Si el empleador o contratista no paga lo acordado, si el compatriota se queda con el trabajo porque cobró menos, o si el amigo no avisó de un trabajo, son situaciones cotidianas que amenazan constantemente los vínculos que se establecen. Se produce un equilibrio frágil, se tejen amistades, pero saben que no son ni duraderas, ni incondicionales.

La combinación de estos elementos va dando forma a los modos de habitar la esquina que la diferencian con otras esquinas como las de Chicago, Los Angeles o Berkeley (Valenzuela 2001, 2003). De acuerdo con los estudios revisados, esas otras esquinas son lugares vinculados principalmente con la búsqueda de trabajo. Ahí llegan los que llevan menos tiempo, los indocumentados y los que tienen poco conocimiento del idioma, como describe Valenzuela $(2001,2003)$. En la esquina de Catedral, en cambio, es necesario tener los papeles, pues los controles de la policía son cotidianos, además, quienes la frecuentan no son solo recién llegados, sino también aquellos que llevan años perpetuando esta forma de trabajo y de vida.

Las relaciones sociales que se establecen también responden a este doble carácter, ya que se trata de relaciones intensas, de amistad, de compañerismo, a la vez que frágiles por estar expuestas al olvido, a los intereses personales y al engaño. Se trata de relaciones que incluyen la idea de lazos débiles y lazos fuertes de Granovetter, pues permiten conseguir trabajos, entregan información importante, a través de los que circula confianza, apoyo y seguridad, 
sin embargo, son simultáneamente vínculos que pueden romperse fácilmente debido a ausencias prolongadas, malos entendidos, distanciamientos y peleas.

Habitar en forma cotidiana la esquina otorga una sensación de seguridad, pese a los controles constantes de la Policía de Investigaciones de Chile (PDI). Los entrevistados saben que están protegidos, 'uno sabe que caminando en esta calle nadie te va a venir a robar o asaltar'. La sensación de seguridad está dada por la apropiación que han hecho del lugar, el conocimiento que tienen sobre las personas que lo habitan y las redes sociales que allí surgen. La seguridad que muestran los migrantes se opone al discurso elaborado por autoridades locales y medios de comunicación que tienden a criminalizar al sector habitado por migrantes (Garcés, 2014). Si para estos últimos, el centro de Santiago habitado por migrantes, es un lugar inseguro y violento, para los primeros es uno de los lugares de la ciudad donde más tranquilos se sienten. La seguridad que expresan es la seguridad que se desprende de estar entre los nuestros.

Entrevistador: ¿Sientes esta calle como tuya? Entrevistado: Me siento más seguro en esta calle, me siento más seguro y protegido, yo sé ya, ya los conozco, cuando uno conoce un sitio, entonces uno se siente más a gusto más tranquilo, más seguro, uno conversa. Uno sabe que caminando en esta calle nadie te va a venir a robar o asaltar, salvo que vengan los carabineros a molestarte $o$ la policía internacional, pero ellos vienen en la noche, cuando hay gente un poco más movida, pero ahí hay que irse. En el día no te va a pasar nada (Arturo, hombre peruano).

Ser parte de la esquina se basa en relaciones frágiles pero muy significativas. Porque las relaciones se pueden romper, es necesario volver constantemente al lugar. Es necesario estar ahí para ser parte de esas redes, pues la precariedad que las caracteriza no resistiría una ausencia prolongada. El que no está ahí, no será llamado, no será convocado por un maestro, no será uno de ellos. El retorno se da de distintas maneras. En algunos casos se trata de personas que tienen trabajos más estables por períodos cortos (un par de semanas) y al terminar el contrato, vuelven a la esquina a esperar que lo llamen o que un amigo le ofrezca un trabajo; otros van todos los días y viven de trabajos esporádicos de horas o días, y cuando este se acaba, regresan a la esquina; otros van después de sus trabajos, pasan por ahí antes de irse a la casa, para saludar a los compatriotas y conversar un rato.

La esquina es un lugar de iguales en medio de las múltiples relaciones desiguales que experimentan diariamente. Si en sus respectivos trabajos son catalogados como inmigrantes peruanos y clase trabajadora, en la esquina son solo compatriotas que viven experiencias similares. Reconocerse como iguales permite generar vínculos, relaciones sociales desde donde emergen formas de apoyo, ayuda, compromiso y solidaridad.

\section{Entrevistador: ¿Sientes que es como el lugar de ustedes? \\ Entrevistado: Sí, sí lo siento porque nos entendemos entre nosotros mismos, en nuestra conversación, la forma de expresarnos, es que hay gente que tú conoces que es gente del pueblo, gente del norte o del sur, entonces nosotros sabemos cómo somos nosotros, como que te sientes seguro, te dan la mano a veces lo invitas a tu piezas, compartes te sientes como en familia, de por medio hay un respeto entre nosotros, nos cuidamos, me siento como que si fuera mi propia ciudad (Reinaldo, hombre peruano).}

Las palabras 'compartes, te sientes como en familia' ejemplifican con claridad el anverso de lo frágil y precario que caracteriza a esta esquina y es probablemente una de las razones que invita a volver. Los lazos afectivos, aunque frágiles, permiten reproducir elementos que se dan dentro de los vínculos intrafamiliares, es decir, seguridad y protección. Esto es parte de la experiencia propia de los inmigrantes y que los distingue de los trabajadores informales del resto de la economía. La posibilidad de que estas relaciones permitan sentirse como en familia, descansa en un hecho clave que es reconocerse como iguales 'nosotros sabemos cómo somos', no nos podemos engañar, no es posible hacerse pasar por alguien no peruano o no migrante. La posibilidad del reconocimiento de lo que se es, más allá de cualquier categoría 
social impuesta (migrante, extranjero, peruano), se convierte en el primer paso para la construcción de una idea de nosotros.

La esquina es el lugar donde se vuelca lo privado, pues reemplaza a la casa como lugar de encuentro con amigos, ya que las piezas en las que viven son muy pequeñas y 'no hay donde estar', como señala uno de los entrevistados. Ello es cierto pues son muchos los que viven o comparten habitaciones pequeñas, por lo que resulta imposible disponer de un lugar propio para descansar o tener el espacio necesario para invitar a un amigo a compartir un rato después del trabajo. La casa o pieza termina siendo solo un lugar para dormir, ya que incluso algunos prefieren comer en el centro porque en sus casas los vecinos chilenos se quejan de los olores cuando ellos cocinan. Aquellas prácticas que realizaban en sus casas en origen, como descansar, comer, relajarse, invitar a amigos o tomarse una cerveza, en Santiago y bajo las condiciones en las que se da la inmigración, resultan imposibles de realizar en los espacios donde viven, y por ende, se vuelcan hacia los espacios públicos. De este modo, elementos que en otras ocasiones suelen definir lo privado, en este contexto se realizan en la calle y en particular, en esta esquina.

La esquina de Catedral es también un lugar para disfrutar del tiempo de relajo y distensión, el tiempo del no trabajo, del ocio, aquel tiempo que queda entre el trabajo y la casa. De ahí que sea un lugar principalmente masculino, pues las mujeres no suelen disponer de ese tiempo libre. Es interesante recordar que el principal lugar donde las mujeres adquieren información y acceso a trabajo es una casa perteneciente a la parroquia Italiana, a muchas cuadras de la Plaza de Armas. Esa casa tiene un portón que la separa de la calle. Ahí las mujeres pueden almorzar y dormir por unos días, cuando recién han llegado. Las mujeres solo pueden acceder libremente a la esquina los fines de semana, pues esos días deja de ser un lugar masculino y se transforma en una vereda de encuentro disponible para todos.

\section{A Modo de Cierre}

Las formas de habitar el centro de la ciudad permiten la apropiación y resignificación del espacio por parte de los migrantes. Los elementos descritos van construyendo un habitar que permite que la esquina se vaya transformando en un lugar propio (nuestro) que la distingue y diferencia del resto de la ciudad. La resignificación que ocurre entra en tensión y conflicto con los otros significados otorgados a la plaza, como el relato de carácter más republicano, con relatos urbanos y modernos que buscan potenciar a la ciudad como ciudad global, con discursos y empeños por parte de la municipalidad de hacer del centro de Santiago un lugar ordenado, limpio y seguro. A su vez, las formas de habitar están marcadas por las condiciones de precariedad y vulnerabilidad que enfrentan los migrantes. El trabajo por día o por tiempos cortos, sea en la construcción, como cargueros en camiones o en la agricultura, marca un ritmo de vida que queda impregnado en las formas de habitar la plaza. La necesidad de estar activando constantemente las redes para ser llamados, la necesidad de estar ahí cuando llegue alguien a buscar trabajadores, la confianza que se requiere para que un connacional lo sume en una cuadrilla, determinan que los lazos sean fuertes, pero simultáneamente precarios. La apropiación del lugar deviene finalmente en un acto reivindicativo, que permite marcar presencia ahí donde se les busca expulsar. La paradoja es que en la medida en que se construye como lugar propio, de encuentro entre iguales, donde la experiencia de ser migrantes es lo que los reúne y convoca, el lugar para la comunidad mayor (chilena) queda indefectiblemente marcado como lugar del otro. La emergencia de un nosotros en el espacio urbano permite reunirlos y convocarlos, pero a la vez es lo que lo vuelve distinguible y separable del resto de la ciudad. Así el espacio muestra otras formas de segregación, incluso ahí donde conviven con los nacionales.

Agradecimientos: Este artículo es parte de los resultados del proyecto Fondecyt $\mathrm{N}^{\mathrm{o}} 1130642$. Agradezco también a los evaluadores del presente artículo, quienes permitieron mejorar sustancialmente la propuesta inicial. 


\section{Referencias Citadas}

Ardener, S. 1993. Women and Space: Ground Rules and Social Maps. Bloomsbury Academic, Nueva York.

Bauman, Z. 2006. Modernidad Líquida. FCE, Buenos Aires.

Benjamin, W.1972. Iluminaciones II. Baudelaire. Un Poeta en el Esplendor del Capitalismo. Editorial Taurus, Madrid.

Bonhomme, M. 2013. Cultura material y migrantes peruanos en Chile: un proceso de integración desde el hogar. Polis Revista Latinoamericana 12:63-84.

Bourdieu, P. 1998. La Dominación Masculina. Anagrama, Barcelona.

Caggiano, S. 2011. Racismo, fundamentalismo cultural y restricción de la ciudadanía: formas de regulación social frente a inmigrantes en Argentina. En Las Migraciones en América Latina. Políticas, Culturas y Estrategias, editado por Novick S. Catálogos, Clacso, Buenos Aires.

Cárdenas, A., F. Link y J. Stillerman 2012. ¿Qué Significa el Trabajo Hoy? Cambios y Continuidades en una Sociedad Global. Catalonia, Santiago.

Castells, M. 1999. La Condición Urbana. Siglo XXI, México D.F.

De Certeau, M. 2010. La Invención de lo Cotidiano.1 Artes de Hacer. Universidad Iberoamericana, México D.F.

Ducci, M.E. y L. Rojas 2010. La pequeña Lima: nueva cara y realidad para el centro de Santiago de Chile. EURE 36:95-121.

Garcés, A. 2014. Contra el espacio público: criminalización e higienización en la migración peruana en Santiago de Chile. EURE 40:141-162.

Harvey, D. 2003. The Condition of Postmodernity. An Enquiry into the Origins of Cultural Change. Blackwell, Massachusetts.

Harvey, D. 1990. Between space and time: reflections on the geographical imagination. Annals of the Association of American Geographers 80:418-434.

Imilan, W. 2014. Restaurantes peruanos en Santiago de Chile: construcción de un paisaje de la migración. Estudios Sociales 48:15-28.

Kuper, H. 2003. The language of sites in the politics of space. En The Anthropology of Space and Place. Locating Culture, editado por S.M. Low y D. Lawrence-Zuñiga, pp. 247-263. Blackwell, Malden.

Lefebvre, H.1991. The Production of Social Space. Blackwell, Londres.

Low, S.M. y D. Lawrence-Zuñiga 2003. The Anthropology of Space and Place. Locating Culture. Blackwell, Malden.

Luque, J.C. 2007. Asociaciones políticas de inmigrantes peruanos y la 'Lima Chica' en Santiago de Chile. Migraciones Internacionales 4:121-150.

Margarit, D. y K. Bijit 2014. Barrios y población inmigrante: el caso de la comuna de Santiago. INVI 8:19-77.
Massey, D. 1994. Space, Place and Gender. University of Minnesota Press, Minneapolis.

Miller, D. 1998. Material Cultures: Why some Things Matter. UCL Press, Londres.

Sassen, S. 2003. Los Espectros de la Globalización. FCE, Buenos Aires.

Schiappacasse, P. 2008. Segregación residencial y nichos étnicos de los inmigrantes internacionales en el área Metropolitana de Santiago. Revista de Geografía Norte Grande 39:21-38.

Stefoni, C. 2013a. Formación de un enclave transnacional en la ciudad de Santiago de Chile. Migraciones Internacionales 7:161-187.

Stefoni, C. 2013b. Los cibercafé como lugares de prácticas trasnacionales: El caso de la maternidad a distancia. Polis Revista Latinoamericana 12:211-227.

Thayer, E. 2011. Trabajo y género: la condición social de inmigrante como referente para la definición de la identidad. En Mujeres Inmigrantes en Chile. Mano de Obra o Trabajadoras con Derechos, editado por C. Stefoni, pp. 75-108. Ediciones Alberto Hurtado, Colección sociología, personas, organizaciones, sociedad, Santiago.

Thayer, E. 2013. Expectativas de reconocimiento y estrategias de incorporación: la construcción de trayectorias degradadas en migrantes latinoamericanos residentes en la Región Metropolitana de Santiago. Polis 12:259-285.

Tijoux, M.E. 2011. Negando al 'otro': el constante sufrimiento de los inmigrantes peruanos en Chile. En Mujeres Inmigrantes en Chile. Mano de Obra o Trabajadoras con Derechos, editado por C. Stefoni, pp. 17-42. Ediciones Alberto Hurtado, Colección sociología, personas, organizaciones, sociedad, Santiago.

Tokman, V. 2001. De la Informalidad a la Modernidad. OIT Chile, Santiago.

Valenzuela, A. 2003. Day labor work. Annual Review of Sociology 29:307-333.

Valenzuela, A. 2001. Day labourers as entrepreneurs? Journal of Ethnic and Migration Studies 27:335-352.

Waldinger, R. 1986. Immigrant enterprise: A critique and reformulation. Theory and society. Special Issue: Structures of Capital 15:249-285.

Waldinger, R. 2008. Between "Here" and "There": immigrant cross-border activities and loyalties. International Migration Review 42/1:3-29.

Wieviorka, M. 2002. El Racismo. Una Introducción. Plural Editores, La Paz.

Zlolniski, C. 2006. Janitors, Street Vendors and Activist. The Lives of Mexican Immigrants in Silicon Valley. University of California Press, California. 